\title{
PENERAPAN DIFFERENTIAL REINFORCEMENT OF ALTERNATIVE BEHAVIOR DAN ANTECENDENTS CONTROL UNTUK MENURUNKAN SCREEN-TIME PADA ANAK DENGAN LANGUAGE DISORDER
}

\author{
Rizqina Permatasari Ardiwijaya ${ }^{1}$ dan Ike Anggraika Kuntoro ${ }^{2}$ \\ ${ }^{1,2}$ Fakultas Psikologi, Universitas Indonesia \\ ${ }^{1,2}$ Fakultas Psikologi, Kampus Baru Univesitas Indonesia, Depok \\ Email: rizqina.permatasari@gmail.com
}

Diserahkan 17 Januari 2018; Diterima 12 Maret 2019; Dipublikasikan 01 April 2019

\begin{abstract}
ABSTRAK
Screen-time merupakan waktu penggunaan media elektronik, seperti televisi, telepon genggam, komputer, tablet atau video games. Beberapa penelitian melaporkan bahwa terdapat hubungan antara screen-time dengan obesitas, masalah atensi, agresi dan language disorder. Penelitian ini bertujuan untuk menurunkan durasi screen-time pada anak dengan menggunakan metode antecedents control dan differential reinforcement of alternative behavior (DRA). Intervensi ini terdiri dari 15 sesi yang berdurasi masing-masing 60 menit. Terdapat sembilan sesi dilakukan oleh peneliti dan enam sesi dilakukan oleh ibu atau pengasuh dengan pendampingan peneliti. Teknik DRAyangdigunakan berupa memberikan perilaku alternatif lain untuk menggantikan screen-time. Perilaku alternatif yang digunakan dalam program intervensi ini adalah keterlibatan dalam permainan terstruktur, yaitu permainan motorik, konstruktif, dan imajinatif (pura-pura). Dalam setiap sesi terdiri dari tiga jenis permainan terstruktur yang masing-masing berdurasi 20 menit. Durasi screen-time dicatat pada lembar observasi screen-time. Teknik antecedents control dilakukan untuk mengondisikan lingkungan sekitar anak agar mendukung keberhasilan intervensi. Adapun program antecedents control dalam penelitian ini dirancang berdasarkan data yang didapat dari pengukuran HOME. Partisipan pada penelitian ini adalah anak laki-laki berusia 2 tahun 11 bulan dengan language disorder. Hasil penelitian menunjukkan bahwa teknik antecedents control dan DRA efektif menurunkan screentime dari 226,25 menit menjadi 57,5 menit per hari.
\end{abstract}

Kata kunci: differential reinforcement of alternative behavior; language disorder; screen-time.

\section{DIFFERENTIAL REINFORCEMENT OF ALTERNATIVE BEHAVIOR TO REDUCING SCREEN TIME DURATION IN CHILDREN WITH LANGUAGE DISORDER}

\begin{abstract}
Screen-time refers to the amount of time using electronic devices, such as television, smartphone, computer, tablet or video game console. Numbers of studies have reported the relationship between children's excessive screen-time with obesity, attention problems, aggression, and language disorder. This study aims to reduce screen-time duration using antecedents control and differential reinforcement of alternative behavior (DRA) techniques. The intervention consists of 15 sessions that 60 minutes in length. There were nine sessions conducted by researchers and six sessions conducted by mother or caregivers with assistance from researchers. The DRA technique used to provide alternative behavior to replace screen-time. Alternative behavior used in this intervention program is a child's involvement in structured play, such as motoric, constructive, and imaginative (pretend play). Each session consists of three types of structured play that are 20 minutes each type of play. Screen-time duration is recorded on the screen-time observation sheet. The antecedents controlis performed to regulate the environment around the child to support the intervention. This technique designed based on data obtained from measurement of HOME. The participant of this study is 2 years and 11-month boy with a language disorder. The result shows that antecedents control and DRAtechniques have reduced thescreen-time effectively, from 226,25 mins to 57,5 mins per day.
\end{abstract}

Keywords: differential reinforcement of alternative behavior; language disorder; screen-time.

\section{PENDAHULUAN}

Screen-time merupakan waktu yang digunakan individu untuk mengakses perangkat elektronik, seperti menonton televisi, bermain video game, menggunakan ponsel atau komputer. Saat ini, screen-time pada anak prasekolah mulai menjadi fokus dari banyak penelitian karena dinilai berdampak buruk bagi perkembangan anak. Penelitian yang dilakukan pada anak usia dini melaporkan bahwa terdapat hubungan antara screen- 
time dengan keterlambatan perkembangan kognitif dan bahasa pada anak.Anak usia dini yang terpapar screentime berlebihan mengalami masalah dalam mempertahankan perhatian (Swing, Gentile, Anderson, \& Walsh, 2010), ingatan jangka pendek, prestasi akademik dalam membaca dan matematika (Barr, Lauricella, Zack, Calvert, 2010; Tomopoulos, et. al, 2010).Selain itu, anak usia dini dengan screen-time berlebihan dilaporkan memiliki kosa kata yang lebih rendah (Zimmerman, Christakis, \& Meltzoff, 2007). Hal ini juga didukung oleh penelitian lain yang menyimpulkan bahwa anak usia dini yang memiliki screen-timelebih dari dua jam setiap hari sejak usia kurang dari satu tahun memiliki risiko yang lebih tinggi untuk mengalami keterlambatan perkembangan bahasa dan kurang tertarik dalam berkomunikasi (Ruangdaraganon, et. al, 2009; Duch, Fisher, Ensari, \& Harrington, 2013). Munculnya masalah bahasa atau komunikasi ini disebabkan karena paparan screen-time mengurangi kuantitas dan kualitas interaksi antara orang tua dan anak (Tanimura, Okuma, Kyoshima, 2007). Sedangkan, pada usia dini anak membutuhkan interaksi langsung dengan individu lain untuk mengembangkan kemampuan bahasa dan kognitif.

Dalam penelitian longitudinal yang dilakukan oleh Pagani, Fitzpatrick, Barnett \& Dubow (2010) dilaporkan bahwa screen-time yang berlebihan pada anak usia dini juga menimbulkan risiko masalah perilaku dikemudian hari (Verlinden et al., 2012). Anak yang terus menerus terpapar televisi memiliki risiko yang lebih tinggi untuk mengalami masalah eksternalisasi. Masalah eksternalisasi pada anak ini muncul akibat paparan televisi yang berlebihan sejak usia dini. Berdasarkan penjelasan di atas, dapat disimpulkan bahwa dampak buruk dari screen-time yang berlebihan pada anak usia dini, tidak hanya mengganggu perkembangan anak saat ini, namun juga mengganggu perkembangan anak dikemudian hari. Oleh sebab itu, screen-time pada anak usia dini perlu dibatasi.

Pada intervensi ini, partisipan yang terlibatberusia2 tahun 11 bulan yang memiliki screen-time empat jam dan diagnosis Language Disorder dan Regulatory Sensory-Processing Disorder (ICDL-DMIC, 2005). Adapun gejala yang ditunjukan oleh partisipan adalah kosakata terbatas, artikulasi belum jelas, dan kurang responsif saat dipanggil. Selain itu, partisipan juga menunjukkan perilaku tantrum, yaitu menangis sambil berteriak, melempar barang (ke lantai atau ke arah orang lain), dan membenturkan kepala (ke lantai atau orang lain). Temper tantrum sendiri merupakan perilaku yang wajar muncul anak yang belum mampu menggunakan bahasa untuk mengekspresikan keinginan dan rasa frustrasinya. Perilaku tantrum ini muncul ketika keinginannya tidak terpenuhi, baik di rumah maupun di tempat umum.
Masalah bahasa dan perilaku yang dialami partisipan dipengaruhi oleh screen-time yang berlebihan jika dibandingkan dengan anak seusianya. Orang tua jarang mengajak anak untuk berinteraksi karena sibuk bekerja. Setiap hari, ia menghabiskan waktu dengan menonton televisi atau YouTube selama empat jam. Sedangkan seharusnya, screen-time yang diberikan pada anak usia diatas dua tahun adalah satu jam setiap hari dengan pendampingan orang tua serta pemilihan program berkualitas (The American Academy of Pediatrics [AAP], 2001). Selain itu, pemberian screen-time berlebihan jelas tidak sesuai dengan tugas perkembangan anak usia dini. Pada usia dini, anak seharusnya belajar untuk berkomunikasi. Jika anak terlalu banyak diberikan screen-time, maka ia akan kehilangan kesempatan untuk mendapatkan stimulasi dari lingkungan secara langsung. Jika hal ini tidak segera ditangani, maka akan berakibat buruk pada kemampuan kognitif, sosial, dan akademis di kemudian hari (Tanimura, Okuma\&Kyoshima, 2007; Ruangdaraganon, et al., 2009; Tomopoulos, et al., 2010). Mengingat hal tersebut, perlu dilakukan intervensi untuk menurunkan perilaku screen-time partisipan.

Pada penelitian Carlson dan Fulton, (2015), dijelaskan bahwa intervensi yang digunakan untuk mengurangi screen-time biasanya melibatkan kombinasi antara pemberian limit-setting dan pengalihan pada aktivitas fisik. Pada beberapa penelitian lainnya, digunakan aktivitas alternatif untuk menggantikan screen-time (Biddle et al., 2014; Bagley, Salmon, \& Crawford, 2006; Salmon, et al, 2008). Screen-time dapat digantikan dengan aktivitas lain, seperti membaca, aktivitas fisik, bermain imaginasi atau semua kegiatan yang dapat mendukung perkembangan bahasa dan fisik serta interaksi sosial dan pertumbuhan anak usia dini (Tandon, et. al, 2011). Oleh sebab itu, program intervensi ini dirancang dengan menggunakan teknik pemberian reinfocer, yaitu differential reinforcement of alternative behavior (DRA). Teknik DRA didefinisikan sebagai suatu prosedur yang digunakan untuk menurunkan atau menghilangkan perilaku yang tidak diinginkan dengan cara memberikan reinforcement pada perilaku lain yang diinginkan (Martin \& Pear, 2015). Beberapa penelitian terkait screen-time menganjurkan untuk mengganti screen-time dengan kegiatan alternatif yang menyenangkan, seperti bermain atau olah raga (Biddle et al., 2014; Bagley, Salmon, \& Crawford, 2006; Salmon, et al, 2008). Oleh sebab itu, pada penelitian ini, reinforcement diberikan pada perilaku terlibat aktif dalam kegiatan bermain. Selain itu, dalam program intervensi ini juga digunakan metode antecedents control dengan tujuan untuk memanipulasi antecedents condition, sehingga perilaku yang diinginkan dapat muncul (Milterberger, 2012). Pemilihan metodeantecedents control didasarkan pada peran 
lingkungan yang besar dalam pembentukan perilaku pada anak usia dini. Berdasarkan pemaparan di atas, peneliti ingin mengetahui efektivitas dari program intervensi modifikasi perilaku dengan teknik antecedents control dan differential reinforcement of alternative behavior (DRA) dalam menurunkan perilaku screen-time pada anak usia dini dengan masalah bahasa.

\section{METODE}

\section{Desain Penelitian}

Penelitian ini merupakan single case dengan $A-B$ design (Comer\& Kendall, 2013). Terdapat empat fase dalam penelitian ini, yaitu persiapan, baseline, intervensi, dan follow-up. Pada persiapan, peneliti melakukan kaji etik, analisis fungsi perilaku, asesmen reinforcement, dan asesmen permainan. Sebelum intervensi dilaksanakan, peneliti melakukan pengambilan data baseline untuk melihat durasi screentime partisipan selama delapan sesi. Setelah hasil baseline stabil, intervensi mulai dilaksanakan selama 15 sesi. Selama pelaksanaan intervensi, durasi screen-time diharapkan dapat menurun. Fase follow-up dilakukan sebanyak delapan sesi, antara fase intervensi dan followup berjarak tiga minggu. Adapun teknik modifikasi perilaku yang digunakan dalam penelitian ini adalah antecedents control dandifferential reinforcement of alternative behavior (DRA).

\section{Partisipan Penelitian}

Penelitian ini melibatkan satu orang partisipan. Ia adalah anak laki-laki berusia 2 tahun 11 bulan. Partisipan memiliki masalah bahasa, ia diagnosis Language Disorder dan Regulatory Sensory-Processing Disorder (ICDL-DMIC, 2005). Sejak bayi, ia menghabiskan empat jam untuk menonton televisi atau YouTube. Tak jarang, orangtua juga menjadikan media elektronik sebagai alat untuk menenangkan atau mengalihkan perhatian partisipan ketika tantrum.

Saat ini, kemampuan bahasa partisipan berada di bawah kemampuan anak seusianya, terutama dalam memproduksi bahasa (production). Ia mampu memproduksi sekitar 34 kosakata, sedangkan pada anak usia 24 bulan seharusnya memiliki 30-50 kosakata (Marotz \& Allen, 2011). Dalam berkomunikasi, ia lebih sering menunjukkan gestur sederhana ketika menginginkan sesuatu. Selain itu, ia sering mengalami kesulitan untuk mengomunikasikan maksud dan perasaannya, sehingga menunjukkan perilaku temper tantrum sebagai wujud dari rasa frustrasinya. Perilaku tantrum yang ditunjukkan, antara lain menangis sambil berteriak, melempar barang (ke lantai atau ke arah orang lain), dan membenturkan kepala (ke lantai atau orang lain). Perilaku tantrum ini muncul ketika keinginannya tidak terpenuhi, baik di rumah maupun di tempat umum.

Partisipan juga menunjukkan adanya indikasi masalah sensori, seperti kakinya yang selalu berjinjit ketika berjalan, sering melompat dan berlarian, serta sulit merespons pada speech sounds (suara manusia). Ia lebih mampu merespons suara yang lantang dibandingkan suara halus. Hal ini mengakibatkan partisipansulit diajak berinteraksi dan cenderung terhanyut dengan dirinya sendiri (self-absorbed). partisipanjarang menoleh saat dipanggil namanya dan sulit untuk ditarik perhatiannya. Ia lebih memilih untuk menonton televisi atau YouTube dibandingkan berinteraksi dengan orang lain.

\section{Instrumen Penelitian}

Dalam penelitian ini, screen-time didefinisikan sebagai pada jumlah waktu yang dihabiskan partisipan untuk menonton, baik dari televisi, telepon genggam maupun tablet dalam satu hari. Informasi mengenai screen-time didapatkan melalui wawancara dan pengisian lembar observasi yang dilakukan oleh ibu atau pengasuh. Pada lembar observasi tersebut ibu atau pengasuh diminta untuk menuliskan durasi screen-time partisipan setiap hari. Lembar observasi screen-time yang digunakan pada program intervensi ini diadaptasi dari penelitian Lauricella, Wartella, dan Rideout (2015). Selain menuliskan durasi screen-time, ibu juga diminta untuk menuliskan beberapa keterangan seperti, jenis perangkat yang digunakan, program yang ditonton, serta pendampingan orang dewasa. Durasi screen-time dihitung dengan menjumlahkan durasi screen-time setiap sesi, kemudian dirata-ratakan. Intervensi akan dianggap berhasil jika partisipan dapat menunjukkan penurunan rata-rata durasi screen-time minimal 60 menit. Dengan demikian, peserta juga akan menunjukkan rata-rata durasi screen-time yang lebih sedikit dibandingkan dengan fase baseline.

Program antecedents control pada penelitian ini dirancang berdasarkan data The Home Observation for Measurement of the Environment (HOME) (Caldwell \& Bradley, 1984). Melalui alat ukur ini dapat diketahui kualitas dan kuantitas stimulasi dan dukungan yang tersedia untuk partisipan di lingkungan rumah. Alat ukur ini diadministrasikan melalui observasi dan wawancara yang dilakukan pada pengasuh utama (ibu dan pengasuh). Adapun skala pada alat ukur ini terdiri dari tanggap rasa dan kata, penerimaan terhadap perilaku anak, pengorganisasian lingkungan, penyediaan mainan, keterlibatan ibu terhadap anak, serta kesempatan variasi asuhan (Totsika \& Sylva, 2004). Adapun contoh item pada alat ukur ini antara lain : 1) apakah ibu menanggapi ocehan anaknya dengan kata-kata selama kunjungan? (skala tanggap rasa dan kata); 2) apakah ibu pernah berteriak kepada anaknya selama kunjungan? (skala penerimaan terhadap perilaku anak); 3) Apakah anak 
diasuh oleh orang yang sama? (skala pengorganisasian lingkungan); 4) apakah terdapat mainan untuk melatih gerak anka? (skala penyediaan mainan); 5) apakah ibu sering mengawasi anak secara langsung atau sambil bekerja? (skala keterlibatan ibu terhadap anak); 6) apakah ayah selalu ikut mengasuh anak setiap hari? (skala kesempatan variasi asuhan). Item pada alat ukur ini diberi skor berdasarkan jawaban atas pertanyaan wawancara semi-struktur dan pengamatan langsung terhadap lingkungan rumah. Selain itu, wawancara semistruktur juga dilakukan pada ibu dan pengasuh untuk melihat peningkatan kemampuan interaksi dan bahasa partisipan.

\section{Prosedur Penelitian}

\section{Persiapan penelitian}

Program intervensi ini telah melalui kaji etik oleh Komite Etik Universitas Indonesia nomor 259/FPsi.Komite Etik/PDP.04.00/2018. Peneliti memberikan lembar persetujuan kepada ibu. Mereka telah memberikan persetujuan untuk terlibat dan mengizinkan anak mereka untuk ikut serta dalam program intervensi ini. Partisipan memiliki kewenangan untuk mencabut keikutsertaan mereka selama program intervensi berlangsung. Selain itu, partisipan juga mengetahui tujuan dan prosedur intervensi.

Sebelum memulai intervensi, peneliti melakukan identifikasi antecedent, behavior, dan consequences (AB-C) dengan hasil sebagai berikut:

Tabel 1. Gambaran Analisis Fungsi Perilaku

\begin{tabular}{lll}
\hline \multicolumn{1}{c}{ Antecedent $(A)$} & $\begin{array}{c}\text { Behavior } \\
(B)\end{array}$ & $\begin{array}{c}\text { Consequences } \\
(C)\end{array}$ \\
\hline $\begin{array}{l}\text { Ibu kurang } \\
\text { memberikan pilihan } \\
\text { kegiatan yang }\end{array}$ & $\begin{array}{l}\text { Menonton } \\
\text { televisi }\end{array}$ & \\
$\begin{array}{l}\text { menarik untuk } \\
\text { dilakukan di rumah. }\end{array}$ & $\begin{array}{l}\text { dan } \\
\text { YouTube }\end{array}$ & $\begin{array}{l}\text { pengasuh } \\
\text { membiarkan }\end{array}$ \\
Ibu memberikan & selama 4 & $\begin{array}{l}\text { perlaku anak. } \\
\text { kebebasan untuk }\end{array}$ \\
mengakses televisi & jam & \\
& perhari. &
\end{tabular}

Peneliti melakukan assessmentreinforcer dan jenis permainan yang disukai oleh partisipan. Peneliti meminta ibu atau pengasuh untuk mengurutkan reinforcer dan jenis permainan mulai dari yang paling disukai hingga yang tidak disukai oleh partisipan. Hasil menunjukkan bahwa penguat yang disukai untuk barang habis pakai (consumables reinforcer), seperti susu, coklat dan sosis. Social reinforcer yang diinginkan oleh partisipan adalah pujian dan gesture, seperti tos dan tepuk tangan. Sedangkan, jenis permainan yang disukai partisipan adalah permainan motorik, konstruktif, dan imajinatif (pura-pura). Selain itu, peneliti juga merancang program dengan menggunakan antecedents control. Antecedents control merupakan manipulasi stimulus antecedentsdengan cara mengeliminasi stimulus yang dapat mengganggu penurunan durasi screen-time.

\section{Baseline}

Fase baseline terdiri dari delapan sesi. Ibu atau pengasuh diminta untuk mencatat durasi screentimepartisipan pada lembar observasi yang telah disediakan. Sedangkan peneliti, hanya bertugas untuk mendampingi ibu atau pengasuh selama melakukan observasi. Pada fase ini tidak diberikan perlakuan khusus ataupun reinforcer. Pada awal fase baseline terdapat pola variabel yang fluktuatif, namun setelah sesi ke-5 pola grafik pola variabel mulai dapat diprediksi. Rata-rata durasi screen-time partisipan adalah 226,25 menit.

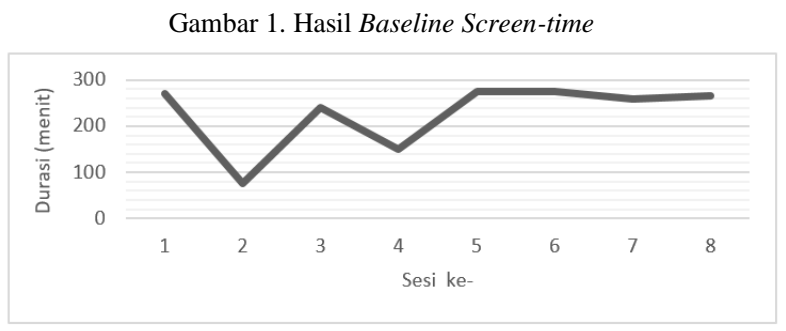

\section{Intervensi}

Fase intervensi terdiri dari 15 sesi yang berdurasi \pm 60 menit. Terdapat sembilan sesi dilakukan oleh peneliti dan enam sesi dilakukan oleh ibu atau pengasuh dengan pendampingan peneliti. Setiap sesi, partisipan diberikan perilaku alternatif yang akan menggantikan screen-time. Perilaku alternatif yang digunakan dalam program intervensi ini adalah keterlibatan dalam permainan terstruktur, yaitu permainan motorik, konstruktif, dan imajinatif (pura-pura). Dalam setiap sesi terdiri dari tiga jenis permainan terstruktur yang masingmasing berdurasi 20 menit. Sebagai contoh, pada sesi pertama partisipan bermain imajinatif (pura-pura) berupa masak-masakan, setelah selesai 20 menit dilanjutkan dengan permainan konstruktif bermain balok, setelah selesai 20 menit dilanjutkan dengan permainan motorik bermain hide-and-seek selama 20 menit. Setiap sesi, partisipan diminta untuk ikut terlibat dalam kegiatan bermain terstruktur yang telah dirancang. Perilaku yang termasuk ke dalam keterlibatan dalam permainan, yaitu mengarahkan pandangan ke arah peneliti, menunjukkan atau memberikan objek kepada peneliti, menunjuk objek, merespons secara memadai permintaan peneliti terkait objek, meniru perilaku peneliti yang berhubungan dengan objek. Setiap sesi, jenis permainan dirancang berbeda-beda agar partisipan tidak bosan. Setelah selesai sesi, partisipan diberikan 
consumable reinforcement. Selain itu, ibu dan pengasuh juga menerapkan program antecedents controlpada setiap sesi intervensi.Berikut rancangan antecedents control yang dilakukan pada setiap sesi intervensi:

Tabel 2. Rancangan Antecedent Control

\begin{tabular}{lll}
\hline \multicolumn{1}{c}{ Antecedent } & $\begin{array}{c}\text { Behavior } \\
\text { (Expected) }\end{array}$ & Consequence \\
\hline $\begin{array}{l}\text { Ibu tidak menempatkan } \\
\text { televisi di kamar tidur. }\end{array}$ & $\begin{array}{l}\text { partisipan } \\
\text { memiliki } \\
\text { aktivitas lain, } \\
\text { sehingga tidak } \\
\text { terpaku pada } \\
\text { Ibu memberikan } \\
\text { peraturan dan batasan } \\
\text { screeen-time. }\end{array}$ & $\begin{array}{l}\text { Derasime } \\
\text { timerang. }\end{array}$ \\
$\begin{array}{l}\text { Partisipan memiliki } \\
\text { jadwal kegiatan sehari- } \\
\text { hari }\end{array}$ & & \\
\hline
\end{tabular}

Saat diberikan pembatasan screen-time, partisipan menunjukkan extinction burst berupa perilaku temper tantrums. Perilaku temper tantrums yang ditunjukkan, yaitu menangis sambil berteriak. Extinction burst diatasi dengan cara tidak memberikan apa yang diinginkan dan menempatkan partisipan dalam kondisi yang aman. Hal ini dilakukan untuk menghindari partisipan melukai diri sendiri dan orang lain selama tantrum.

\section{Follow-up}

Tujuan dari follow-up ini adalah untuk mengetahui apakah perubahan yang dicapai selama program bertahan ketika program intervensi telah usai. Fase follow-up dilakukan tiga minggu setelah program intervensi selesai. Pada sesi follow-up, pemeriksa melakukan pengukuran kembali pada target perilaku dengan cara observasi. Observasi dilakukan tanpa adanya perlakuan khusus dan reinforcer. Selain itu, dilakukan wawancara pada ibu dan pengasuh untuk melihat peningkatan kemampuan interaksi dan bahasa partisipan.

\section{Teknik Analisis Data}

Analisis data dalam penelitian ini dilakukan dengan cara analisis visual pada grafik durasi screen-time. Tujuan dari cara analisis ini adalah untuk mengetahui pengaruh dari modifikasi perilaku yang dilakukan terhadap perilaku screen-time. Fitur analisis visual yang digunakan adalah level dan trendline, dan immediacy of effect (Kratochwill, et al. 2010). Level merupakan ratarata skor dari semua data yang didapatkan pada tiap fase. Trendline adalah garis lurus yang menunjukkan persebaran data dari waktu ke waktu. Sementara itu, immediacy of effect adalah perubahan level di antara tiga poin data terakhir di suatu fase dan tiga poin data pertama di fase berikutnya. Dengan kata lain, dari immediacy of effect, kita dapat melihat efeknya langsung terlihat dengan jelas.

\section{HASIL DAN PEMBAHASAN}

Partisipan menyelesaikan 15 sesi intervensi yang telah dirancang. Berikut hasil program intervensi :

Gambar 2. Analisis Grafik pada Berbagai Fase

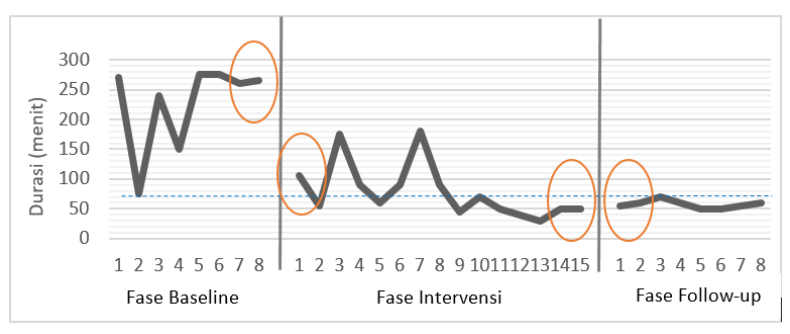

Berdasarkan grafik di atas, dapat dilihat bahwa terdapat level dan trend yang cenderung turun pada perilaku screen-time. Rata-rata persentase screen-time pada fase baseline adalah 226,25 menit. Sedangkan, pada fase intervensi terdapat dua poin data yang mengalami kenaikan drastis, yaitu sesi ke-3 dan ke-7. Pada saat pelaksanaan sesitersebut, partisipan menonton televisi pada malam hari hampir 120 menit. Ibu atau pengasuh kesulitan untuk mengalihkan perhatian agar tidak menonton televisi pada malam hari. Hal ini disebabkan karena ibu dan ayah kelelahan sepulang bekerja, sehingga mereka tidak memiliki tenaga untuk menemani partisipan bermain atau mengatasi tantrum partisipan ketika dilarang menonton televisi. Meski demikian, setelah sesi ke-8 ibu dan pengasuh mulai bisa lebih tegas menerapkan peraturan agar partisipan tidak terlalu lama menonton televisi pada malam. Oleh sebab itu, pada tahap ke-3 rata-rata durasi screen-time partisipan mulai menurun menjadi 44 menit sesuai dengan target intervensi ( $\leq 60$ menit).

Secara keseluruhan, terdapat penurunan rata-rata durasi screen-time partisipan sebesar 147,58 menit dibandingkan dengan fase baseline (226,25 menit).Mempertimbangkan level yang dan trend yang menurun untuk perilaku screen-time dapat disimpulkan bahwa program modifikasi perilaku yang dilakukan terbukti mampu menurunkan durasi screen-time partisipan. Selain itu, lingkaran pada pada grafik menunjukkan bahwa program modifikasi perilaku yang diterapkan pada partisipan memberikan efek yang cukup cepat (immediate). Hal ini juga kemungkinan disebabkan oleh intervensi ini melibatkan aktivitas lain yang berlangsung selama 60 menit untuk menggantikan screen-time. Pada fase baseline, poin data terakhir pada grafik berada di atas. Sedangkan, ketika program intervensi dimulai poin data awal pada grafik berada di bawah. Hal ini berarti terdapat penurunan screen-time 
dari fase baseline ke intervensi. Selain itu, jarak antara poin dataterakhir fase intervensi dan poin data awal pada fase follow-up tidak menunjukkan perbedaan yang signifikan. Dengan kata lain, durasi screen-time partisipan tetap bertahan dari fase intervensi hingga fase follow-up. Meskipun hasil rata-rata durasi screen-time pada fase follow-up menunjukkan adanya sedikit peningkatan, yaitu 57,5 menit. Namun, peningkatan tersebut tidak signifikan dan masih sesuai dengan target perilaku yang ditetapkan, yaitu $\leq 60$ menit.

Pelaksanaan rancangan antecedents control memiliki beberapa hambatan. Pada awal intervensi, terjadi beberapa lonjakan kenaikan durasi screen-time. Hal ini disebabkan karena ibu dan pengasuh masih beradaptasi, sehingga masih belum bisa konsisten dalam melaksanakan program intervensi. Pengasuh juga terlihat kurang mampu menangani perilaku tantrum yang muncul akibat extinction burst. Ketika partisipan tantrum, pengasuh cenderung mudah menyerah untuk memberikan screen-time. Berdasarkan penelitian, hal ini dinilai wajar karena perilaku sedentary yang sudah menetap (contoh menonton televisi, YouTube, bermain games atau social media) kemungkinan sulit diubah. Perilaku tersebut cenderung sudah menjadi komponen kebiasaan yang kuat (Biddle et al., 2014), sehingga butuh proses dan pengulangan untuk menerapkan pola perilaku yang baru. Perubahan perilaku ibu dan pengasuh mulai terlihat setelah dilakukan evaluasi. Pendampingan pada ibu dan pengasuh selama pelaksanaan intervensi ini membuat ibu dan pengasuh termotivasi untuk terlibat aktif dalam intervensi ini. Sehingga pada sesi ke-8, ibu dan pengasuh kembali berkomitmen dan bersungguh-sunguh menjalankan program intervensi ini.

Hasil dari penelitian ini tidak hanya menunjukkan durasi screen-time, namun partisipan juga mulai menunjukkan ketertarikan untuk berinteraksi dengan orang lain selama kegiatan bermain. Sebelumnya, partisipan cenderung tidak tertarik untuk berinteraksi dengan orang lain (self-absorbed). Namun setelah intervensi, partisipan mulai menunjukkan ketertarikan untuk berinteraksi, bahkan beberapa kali ia mulai menunjukkan inisiasi untuk berinteraksi. Partisipan juga mulai mampu mengucapkan satu kalimat dengan lengkap dan konsisten (S-P-O). Selain itu, dengan melibatkan ibu dan pengasuh dalam program intervensi ini, membantu mereka untuk berlatih cara berinteraksi dan bermain dengan partisipan. Setelah program intervensi selesai, ibu dan pengasuh dapat melanjutkan hal yang diajarkan selama intervensi dalam kehidupans hari-hari.

Penelitian ini tentu saja tidak luput dari keterbatasan. Adapun keterbatasan dari penelitian ini terkait keterlibatan ayah. Dalam penelitian ini, ayah tidak dilibatkan karena kesibukannya yang tidak memungkinkan untuk ikut terlibat. Selama intervensi ayah menghambat penerapan program antecedents control. Beberapa kali ayah memberikan screen-time padahal seharusnya tidak boleh diberikan. Oleh sebab itu, ayah sebaiknya diberikan penjelasan terkait program intervensi agar bisa menunjukkan perilaku yang sejalan dengan ibu dan pengasuh. Selain itu, kebiasaan partisipan untuk menonton televisi ketika makan belum bisa ditangani.

\section{SIMPULAN}

Hasil dari penelitian ini menunjukkan bahwa 15 sesi intervensi modifikasi perilaku dengan menggunakan teknik antecedents control dan differential reinforcement of alternative behavior (DRA)terbukti mampu menurunkan durasi screen-time. Hasil tersebut sesuai dengan beberapa penelitian lain yang menggunakan kegiatan alternatif untuk menurunkan screen-time pada anak (Biddle et al., 2014; Bagley, Salmon, \& Crawford, 2006; Salmon, et al, 2008). Dalam penelitian sebelumnya, terdapat beberapa pilihan kegiatan alternatif yang dapat menggantikan screentime, seperti membaca, aktivitas fisik, bermain imaginasi atau semua kegiatan yang dapat mendukung perkembangan dan pertumbuhan anak (Tandon, et. al, 2011). Kegiatan yang dipilih dalam penelitian ini adalah kegiatan bermain terstruktur. Kegiatan ini dipilih sesuai dengan tugas perkembangannya, anak usia dini masih berada dalam tahapan bermain. Peran bermain dalam pengembangan anak usia dini berkaitan dengan banyak aspek perkembangan, terutama bahasa (Lewis, Boucher, \& Lupton, 2000). Dari kegiatan tersebut, perilaku yang di-reinforced adalah keterlibatan dalam kegiatan bermain terstruktur.

Peran ibu dan pengasuh juga turut memberi kontribusi dalam perubahan perilaku partisipan. Pada awal intervensi, ibu cenderung tidak konsisten dalam menerapkan peraturan pembatasan screen-time pada partisipan. Selain itu, mereka juga memiliki daya juang yang rendah ketika menghadapi rengekan, tangisan, atau perilaku tantrum partisipan. Mereka cenderung memberikan sesuatu yang diinginkan oleh partisipan tanpa memikirkan akibatnya bagi partisipan. Pemberian psikoedukasi terkait pentingnya pembatasan screen-time terhadap perkembangan partisipan dan pelatihan interaksi dengan partisipan membantu kelancaran dan keberhasilan program intrevensi ini. Selain itu, partisipan yang berada pada tahap perkembangan early childhood membuat perilaku yang sudah terbentuk saat ini masih bisa diubah.

Pada penelitian selanjutnya, peneliti menyarankan untuk memastikan komitmen dari kedua orangtua, tidak hanya ibu tapi juga ayah. Ayah harus dilibatkan agar bisa mendukung keberhasilan program intervensi. Selain itu, pada penelitian ini hasil rata-rata durasi screen-time 
pada fase follow-up menunjukkan adanya sedikit peningkatan. Oleh sebab itu, akan lebih baik jika penelitian berikutnya diterapkan desain A-B-A-B untuk memastikan bahwa efek dari intervensi bisa menetap.

\section{DAFTAR PUSTAKA}

American Academy of Pediatrics, Committee on Public Education. (2001). Children, adolescents, and television.Pediatrics, 107(2):423-426.

Bagley, S., Salmon, J. O., \& Crawford, D. (2006). Family Structure and Children's Television Viewing and Physical Activity. https://doi.org/10.1249/01.mss.0000218132.68268.f4

Biddle, S. J. H., Petrolini, I., \& Pearson, N. (2014). Interventions designed to reduce sedentary behaviours in young people: A review of reviews. British Journal of Sports Medicine, 48(3), 182-186. https://doi.org/10.1136/bjsports-2013-093078

Caldwell, B., \& Bradley, R. (1984). Home Observation for Measurement of the Environment (HOME)revised edition. Little Rock, AR: University of Arkansas, Little Rock

Carlson, A. S. A., \& Fulton, J. E. (2015). Influence of Limit-Setting and Participation in Physical Activity on Youth Screen Time, 126(1). https://doi.org/10.1542/peds.2009-3374

Comer, J. \& Kendall, P. C. (2013). The Oxford Handbook of Research Strategies for Clinical Psychology. New York: Oxford University Press.

Christakis D. A, Zimmerman F. J, \& Garrison M. M. (2007). Effect of Block Play on Language Acquisition and Attention in Toddlers A Pilot Randomized Controlled Trial. Arch Pediatr Adolesc Med, 161(10): 967-971.

Duch, H., Fisher, E. M., Ensari, I., \& Harrington, A. (2013). Screen time use in children under 3 years old. The International Journal of Behavioral Nutrition and Physical Activity, 10, 102. https://doi.org/10.1186/1479-5868-10-102

ICDL. (2005). Diagnostic Manual for Infancy and Early Childhood. Bethesda, MD: The Interdiciplinary Council on Development and Learning Disorder.

Kratochwill, T. R., Hitchcock, J., Horner, R. H., Levin, J. R., Odom, S. L., Rindskopf, D. M \& Shadish, W. R. (2010). Single-case designs technical documentation. Diunduh dari http://ies.ed.gov/ncee/wwc/pdf/wwc_scd.pdf

Lauricella, A. R., Wartella, E., \& Rideout, V. J. (2015). Journal of Applied Developmental Psychology Young children's screen time: The complex role of parent and child factors. Journal of Applied Developmental Psychology, 36, 11-17. https://doi.org/10.1016/j.appdev.2014.12.001
Lewis, Jill Boucher, Laura Lupton, V. (2000). Relationships between symbolic play, functional play, verbal and non-verbal ability in young children. International Journal of Language \& Communication Disorders, 35(1), 117-127. https://doi.org/10.1080/136828200247287

Marotz, L. R \& Allen, K. E. (2011). Developmental Profiles: Pre-Birth Through Adolescence $\left(7^{\text {th }}\right.$ Editio). Belmont, CA: Wadsworth, Cengage Learning.

Martin, G. \& Pear, J. (2015). Behavior Modification: What It Is and How to Do It (10th Ed.). New Jersey: Pearson Education, Inc.

Miltenberger, R. G. (2012). Behavior Modification: Principles and Procedures (ed. 5). Belmont, CA: Wadsworth Cengange Learning.

Pagani, L. S, Fitzpatrick, C, Barnett, T.A, Dubow, E. (2010). Prospective associations between early childhood television exposure and academic, psychosocial, and physical well-being by middle childhood. Arch Pediatr Adolesc Med,164(5):425431

Ruangdaraganon, N., Chuthapisith, J., Mo-suwan, L., Kriweradechachai, S., Udomsubpayakul, U., \& Choprapawon, C. (2009). Television viewing in Thai infants and toddlers: Impacts to language development and parental perceptions. BMC Pediatrics, 9, 2-7. https://doi.org/10.1186/14712431-9-34.

Salmon, J., Ball, K., Hume, C., Booth, M., \& Crawford, D. (2008). Outcomes of a group-randomized trial to prevent excess weight gain, reduce screen behaviours and promote physical activity in 10-yearold children: Switch-Play. International Journal of Obesity, 32(4), 601-612. https://doi.org/10.1038/sj.ijo.0803805

Sosa, A.V. (2016). Association of the Type of Toy Used During Play with the Quantity and Quality of Parent-Infant Communication. JAMA Pediatr, 170(2):132-137.

Swing, E. L., Gentile, D. A., Anderson, C. A., \& Walsh, D. A. (2010). Television and Video Game Exposure and the Development of Attention Problems. Pediatrics, 126(2), 214-221. https://doi.org/10.1542/peds.2009-1508

Tandon, P. S., Zhou, C., Lozano, P., \& Christakis, D. A. (2011). Preschoolers' total daily screen time at home and by type of child care. Journal of Pediatrics, 158(2), 297-300. https://doi.org/10.1016/j.jpeds.2010.08.005.

Tanimura, M, Okuma, K, \&Kyoshima, K. (2007). Television viewing, reduced parental utterance, and delayed speech development in infants and young children. Arch Pediatr Adolesc Med, 161(6):618619. 
Tomopoulos, S, Dreyer, B.P, Berkule S, Fierman, A. H, Brockmeyer, C, \&Mendelsohn, A.L. (2010). Infant media exposure and toddler development. Arch Pediatr Adolesc Med, 164(12):1105-1111.

Totsika, V., \& Sylva, K. (2004). The Home Observation for Measurement of the Environment Revisited, 9(1), 25-35.

Verlinden, M., Tiemeier, H., Hudziak, J. J., Jaddoe, V. W. V., Raat, H., Guxens, M., ... Jansen, P. W. (2012). Television Viewing and Externalizing Problems in Preschool Children. Archives of Pediatrics \& Adolescent Medicine, 166(10), 919925. https://doi.org/10.1001/archpediatrics.2012.653

Zimmerman, F. J., Christakis, D. A., \& Meltzoff, A. N. (2007). Television and DVD/video viewing in children younger than 2 years. Archives of Pediatrics and Adolescent Medicine, 161(5), 473-479. https://doi.org/10.1001/archpedi.161.5.473 